\title{
Simultaneous I nfestation of a Buffalo calf with Ascaris and strogyloides: A case study
}

\author{
A. K. Samal, P. B. Patra ${ }^{1}$ and Biswa Ranjan Maharana \\ Indian Veterinary Reasearch Institute, Izatnagar - 243122, UP, India. \\ 1. State Department of AH and VS, Govt. of Orissa, Orissa, India. \\ * Corresponding author email : amir_samal@yahoo.co.in \\ Published online 30-04-2011
}

\begin{abstract}
Toxocara vitulorum occurs in the small intestine of Indian buffalo, and is found in many places of world. Small intestinal infestation with Strongyloides papillosus occurs in ruminants. However, we diagnosed a nondescript Indian buffalo calf infested simultaneously with Toxocara vitulorum and Strongyloides papillosus and treated it with standard regimen and found the subject cured.
\end{abstract}

Key words: Ascaris, Buffalo, Infestation,Strongyloides.

\section{Introduction}

One month old nondescript buffalo calf was presented to us with a history of intermittent diarrhoea, poor growth, dullness and anorexia. We checked the body temperature, pulse rate, respiration rate of the subject and found them to be normal. Then, we collected the faecal sample of the buffalo calf directly from the rectum and examined it fresh for any suspected gastrointestinal parasitism.

\section{Materials and methods}

Macroscopic Examination of Faecal sample: Nearly $10 \mathrm{~g}$ of faecal sample was directly collected from the rectum of the subject and was examined physically for any abnormality. The color of the faeces is muddy, the consistency was semi-solid with streaks of mucus and the odor of the sample was characteristically evil.

Microscopic Examination of faecal sample: Samples are prepared for the microscopic examination of the faeces by following direct smear method and Centrifugal flotation method as per the standard protocol. The Samples were examined first under 10X objective with 10X eye piece lenses and then under 45X objective with 10X eye piece lenses of a binocular compound microscope of Ajay Optik 03-A-3076 model and photographs were taken using a digital camera of Sony Cyber-Shot DSC-w120 model.

\section{Results and Discussion}

The rectal temperature, pulse rate and respiration rate of the buffalo calf were found $101.2^{\circ} \mathrm{F}, 60$ per minute and 24 per minute which were within the normal range respectively. In the faecal sample examination by direct smear method, we found eggs of Toxocara vitulorum and Strongyloides papillosus in the same microscopic field. In the centrifugal floatation method, however, we got the eggs of Toxocara vitulorum in huge number with insignificant no.of Strongyloides papillosus eggs. From microscopic examination of faecal sample of the buffalo calf we confirmed the condition to be a simultaneous infestation of the subject with Toxocara vitulorum and Strongyloides papillosus.

Accordingly, we asked the owner of the animal to bring the fresh faecal sample of the dam of the buffalo calf. After examination of the faeces of the dam we found only eggs of Strongyloides papillosus and no eggs of Toxocara vitulorum. So, we treated the calf with Piperazine hexahydrate @ 300mg/Kg body weight[Piperazine Hexahydrate solution $45 \%$ w/v(TTK) $20 \mathrm{ml}$ total dose] orally and with Levamisole hydrochloride @ $7.5 \mathrm{mg} / \mathrm{Kg}$ body weight [Lemasol-75 (Ranbaxy)3ml] subcutaneously. As supportive therapy we administrated $1 \mathrm{ml}$ of Tribivet (Intas Pharmaceuticals) intra muscularly on alternate days for three times to the calf .For treating the dam against Strongyloides papillosus, we administered Fenbendazole @ 5mg/Kg body weight[Fentas 1.5g bolus (Intas Pharmaceuticals)total dose] and $5 \mathrm{ml}$ of Tribivet was administered Intra muscularly on alternate days for three times to the dam as a supportive therapy. After, the first dose of piperazine in the evening, two adult Toxocara vitulorum worms were expelled in the faeces of the calf in the next morning. Again, we measured the length of the worms and found one of the worm measured approximately 


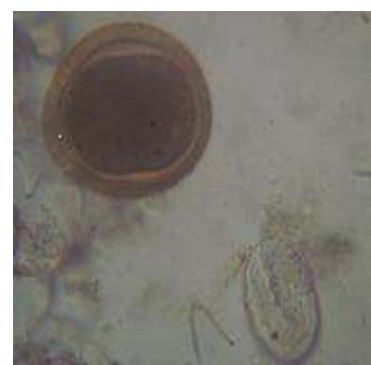

Figure -1 : Egg of Toxocara vitulorum and larvated egg of Strongyloides spp. in fecal sample preparation ofthe buffalo calf. (Direct Smear method)

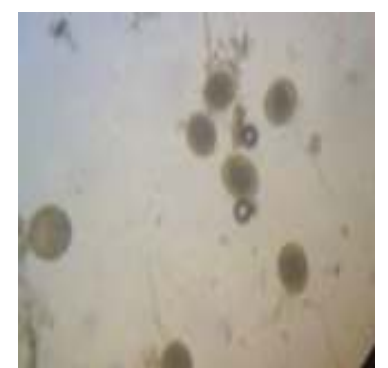

Figure-2. Huge no of Toxocara vitulorum eggs from the feacal sample of the buffalo calf: centrifuga floatation method, 10X.
$25 \mathrm{~cm}$. and another worm approximately $29 \mathrm{~cm}$. (figure) which conforms to the normal length of Toxocara vitulorum worms. The expulsion of the adult worms reinforced the efficacy of our line of treatment.

After 20 days we again examined the faecal sample of both the calf and its dam for presence of parasitic ova and found the samples negative for any parasitic ova. This result showed that the calf was apparently cured of the simultaneous infestation with Toxocara vitulorum and Strongyloides papillosus. Further, this showed the dam to be cured of the infestation with Strongyloides papillosus after the treatment.

Infestation of buffalo calves with either Toxocara vitulorum or Strongyloides papillosus have been previously reported. But here in this case of buffalo calf we got simultaneous infestation with both the worms. This is because adults of Toxocara vitulorum are exclusively found in calves and prenatal

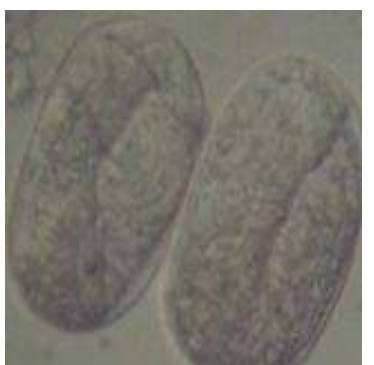

Figure -3: Larvated eggs of Strongyloides papillosus in the faecal sample of the dam: Centrifugal floatation method

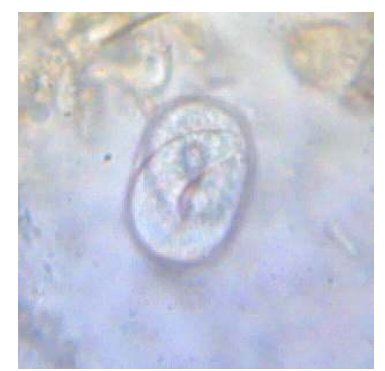

Figure -4: Larvated egg of Strongyloid papillosus found in faecal sample of the dam: Direct Smear method, 10X $45 \mathrm{X}$

and transmammary infections constitutes the major routes of the parasite. Finding of strongyloides eggs may be due to either percutaneous or oral route of infection.Further studies regarding the interaction of the two worms within the animal body will definitely help to illuminate whether the two worms have any synergistic pathogenic effect.

\section{References}

1. Soulsby, E.J.L1., (1982). Helminths, Arthropods and Protozoa of Domesticated Amials, $7^{\text {th }}$ edn, Bailliere Tindall, An imprint of Elsevier 110 Greycoat Place, London SW1P 1SB.pp.155, 169, .765-66

2. Urquhart, G.M. et al (1987). Veterinary Parasitology, Longman Scientific and Technical, Longman Group UK Limited, Essex CM20 2JE, England.pp.64.

3. Chakrabarti, A. (2003). Text Book of Clinical Veterinary Medicine, $2^{\text {nd }}$ edn, Kalyani Publishers, 1/1 Rajinder Nagar, Ludhiana-141008.pp.84,100, 108.

4. Anonymous. (2004-05). Current Indian Veterinary Index; Vol 4, Paico Press,Jew street,Kochi-35 .1 : pp.89,91,97, 269. 